Book review

(C) Journal of International Students

Volume 11, Issue 4 (2021), pp. 1003-1005

ISSN: 2162-3104 (Print), 2166-3750 (Online)

doi: $10.32674 /$ jis.v11i4.4020

ojed.org/jis

\title{
Virtual Internationalization in Higher Education
}

Elisa Bruhn, 2020. WBV.

ISBN: 978-3-7639-6194-8

Reviewed by Minh Ngoc Tran, Thu Dau Mot University, Vietnam

Recently, the COVID-19 pandemic has severely disrupted every sphere of life including the educational sector. Academic institutions globally, especially higher education institutions, have been forced to seek alternative ways of operating, not only to respond to the current disruption but also to deal with ongoing challenges from the pandemic. The worldwide lockdown has accelerated the use of digital technologies, which had already been a key trend before the pandemic. The global online teaching and learning surge calls for comprehensive theoretical approaches related to digitalization and internationalization, which could help higher education institutions, faculty, and practitioners make the most of digital tools and technologies.

Virtual Internationalization in Higher Education, the first volume in the series Innovative Hochschule: digital - international - transformativ, offers an alternative perspective on the virtual internationalization (VI) of higher education by covering multiple aspects and dimensions of higher education. The book is converted from Elisa Bruhn's doctoral dissertation, through which she identified approaches to combining digital technology and an international dimension in higher education, seeking to develop a comprehensive conceptual model of VI for higher education.

Virtual Internationalization in Higher Education is organized into seven chapters that effectively ground the research and coherently present the author's argument. The first chapter introduces the research's aim of exploring various aspects related to how and why digital technology and an international dimension in higher education are combined. 
The second chapter brings together concepts associated with virtuality, or virtual reality - a simulated environment generated by computer technology, digitalization, and internationalization - laying the theoretical foundations for the study. The author illustrates the growing popularity of digital technology and virtuality in the higher education sector. Also included in the chapter is an explanation of the connections between digitalization and internationalization. A definition of VI, which is modified from an existing definition of internationalization, is provided.

Chapter 3, Literature Review, emphasizes instances or aspects of strategic internationalization and digitalization that peer-reviewed literature fails to capture, especially such practices as individual research projects. The author then presents the six components of the comprehensive internationalization $(\mathrm{CI})$ model: (a) articulated institutional commitment; (b) administrative leadership, structure, and staffing; (c) curriculum, co-curriculum, and learning outcomes; (d) faculty policies and practices; (e) physical student mobility; and (f) collaboration and partnerships. The last section highlights the contributions of Bruhn's research to the field.

The author provides a transparent narrative of the research, including rationales for choosing conference proceedings as a document type and content analysis as a data analysis method in the next chapter. Conference proceedings serve as platforms where various actors, including researchers, practitioners, professionals, and administrators, present and discuss their practices. The diversity of conference attendance allows for an exploration of the phenomena from diverse perspectives, from the institutional to individual level. The analytic step-by-step process for analyzing the corpus and validity and reliability considerations were described in great detail.

The results of the content analysis, including descriptions of the sample, are presented in Chapter 5. Based on different components of the CI model, the author outlines the VI model, which comprises seven categories (six categories of the CI models and a new component-fully online and distance education) in two dimensions: (a) information and communications technology (ICT) and internationalization, and (b) ICT and an international dimension for broader aims.

Chapter 6 discusses the findings of the study and presents the model of VI. The first section presents concepts and themes related to virtualization and internationalization identified from the corpus, affirming the association between the two aspects in higher education. These are followed by a display of the means and practices used in each of the six categories of the VI model. The author emphasizes that ICT is used in much the same way for internationalization-related purposes and broader aims in three categories of the VI model: (a) curriculum, cocurriculum, and learning outcomes; (b) faculties' policies and practices; and (c) physically mobile students. However, there are differences in the uses of ICT for an internationalization dimension and broader aims in the other three categories. The next section presents the aims and functions of the combination of ICT and an internationalization dimension. The author closes the chapter by reevaluating the strength and limitations of the sampling strategies and the analytical approaches. 
The book concludes with Chapter 7, which presents key findings and implications of the VI model, highlighting contributions of the model to the internationalization discourse. The chapter also indicates aspects of the VI model that have been overlooked by the scholarly literature, such as curricula, online and distance education, and outbound physical student mobility.

Through Virtual Internationalization in Higher Education, Bruhn has achieved her aim of developing a comprehensive conceptual model of VI for higher education. The model offers an analytic approach for further research and practice on integrating ICT and an internationalization dimension of higher education. As the volume of the first series Innovative Hochschule: digitalinternational - transformativ, the book provides the foundations for in-depth discussions of internationalization in higher education in the volumes that follow. It is a valuable resource for scholars who are interested in the internationalization of higher education and practitioners who seek to use digital technologies strategically in the internationalization process.

Due to the COVID-19 pandemic, the VI of higher education has now become the "new normal," with academic staff and students working remotely, and lectures and assessments being shifted online. While this physical to virtual transition lays down challenges for higher education institutions, faculty, students, and professional staff, the current juncture provides valuable opportunities for transformation. Bruhn's book highlights key aspects of VI and suggests directions for future development. Postpandemic, internationalization - as predicted by the author-may remain a hybridity of the virtual and physical space, but through choice rather than necessity.

MINH NGOC TRAN, PhD, is a lecturer at Thu Dau Mot University in Vietnam. Her research interests include international education, higher education, plagiarism, and academic integrity. Her doctoral research focused on perceptions of plagiarism held by Vietnamese and local postgraduate students at a New Zealand university. She can be reached via email at minhtn@tdmu.edu.vn. 